\title{
Temperature Dependences of the Electrical Resistivity on the Heusler Alloy System $\mathrm{Ni}_{2} \mathrm{MnGa}_{1-x} \mathrm{Fe}_{x}$
}

\author{
Yoshiya Adachi ${ }^{1, *}$, Yuki Ogi ${ }^{1}$, Noriaki Kobayashi ${ }^{2}$, Yuki Hayasaka ${ }^{3}$, Takeshi Kanomata ${ }^{4}$, \\ Rie Y Umetsu ${ }^{5}, \mathrm{Xiao}_{\mathrm{Xu}}{ }^{6}$ and Ryosuke Kainuma ${ }^{6}$ \\ 1 Graduate School of Science and Engineering, Yamagata University, Yonezawa 992-8510, Japan; \\ ogilab1016@gmail.com \\ 2 Faculty of Engineering, Yamagata University, Yonezawa 992-8510, Japan; noriaki.k728@gmail.com \\ 3 Faculty of Engineering, Tohoku Gakuin University, Tagajo 985-8537, Japan; foxcity.yuki@gmail.com \\ 4 Research Institute for Engineering and Technology, Tohoku Gakuin University, Tagajo 985-8537, Japan; \\ kanomata@mail.tohoku-gakuin.ac.jp \\ 5 Institute for Materials Research, Tohoku University, Sendai 980-8577, Japan; rieume@imr.tohoku.ac.jp \\ 6 Department of Materials Science, Graduate School of Engineering, Tohoku University, Sendai 980-8579, \\ Japan; xu@material.tohoku.ac.jp (X.X.); kainuma@material.tohoku.ac.jp (R.K.) \\ * Correspondence: adachy@yz.yamagata-u.ac.jp; Tel.: +81-238-26-3381
}

Received: 10 August 2017; Accepted: 28 September 2017; Published: 3 October 2017

\begin{abstract}
Temperature dependences of the electrical resistivity have been measured on the Heusler alloy system $\mathrm{Ni}_{2} \mathrm{MnGa}_{1-x} \mathrm{Fe}_{x}$. The phase diagram of $\mathrm{Ni}_{2} \mathrm{MnGa}_{1-x} \mathrm{Fe}_{x}$ was constructed on the basis of the experimental results. The structural and magnetic transition temperatures are consistent with those previously determined by magnetic measurements. The changes of the electrical resistivity at the martensitic transition temperature, $\Delta \rho$, were studied as a function of Fe concentration $x$. The $\Delta \rho$ abruptly increased in the concentration range between $x=0.15$ and 0.20 . The magnetostructural transitions were observed at $x=0.275,0.30$, and 0.35 .
\end{abstract}

Keywords: ferromagnetic shape memory alloy; martensitic transition; electrical resistivity; Heusler alloy; Fe-doped $\mathrm{Ni}_{2} \mathrm{MnGa}$

\section{Introduction}

Recently, Ni-Mn based ferromagnetic shape memory alloys (FSMAs) with full Heusler-type structure have attracted much attention because of their potential applications in smart materials. These Heusler alloys exhibit a giant field-induced shape memory effect, large magnetoresistance, and large magnetocaloric effect [1-6]. Among FSMAs with a Heusler-type (L2 1 -type) structure, the stoichiometric compound $\mathrm{Ni}_{2} \mathrm{MnGa}$ has been the most studied. $\mathrm{Ni}_{2} \mathrm{MnGa}$ orders ferromagnetically with the Curie temperature $T_{C}=365 \mathrm{~K}$ [7]. On cooling, the premartensitic phase appears below $T_{\mathrm{p}}=260 \mathrm{~K}$. With further decrease of temperature, $\mathrm{Ni}_{2} \mathrm{MnGa}$ undergoes a first-order martensitic transition at $T_{\mathrm{M}}=200 \mathrm{~K}$ [7]. Recently, Singh et al. performed a high-resolution synchrotron X-ray powder diffraction study for $\mathrm{Ni}_{2} \mathrm{MnGa}$ and discussed the incommensurate nature of the modulate structures of the premartensitic (intermediate) and martensitic phases [8,9]. The ferromagnetic state remains below $T_{\mathrm{M}}$. The spontaneous magnetization of $\mathrm{Ni}_{2} \mathrm{MnGa}$ just below $T_{\mathrm{M}}$ is larger than that just above $T_{\mathrm{M}}$.

The $T_{\mathrm{C}}, T_{\mathrm{p}}$, and $T_{\mathrm{M}}$ of $\mathrm{Ni}_{2} \mathrm{MnGa}$ can be tuned in a wide range by doping with a fourth element. For $\mathrm{Ni}_{2} \mathrm{Mn}_{1-x} \mathrm{Cu}_{x} \mathrm{Ga}(0 \leq x \leq 0.4)$ [10], $T_{M}$ increases with increasing the concentration $x$, while $T_{C}$ decreases with $x$. With further increase of $x$, the magnetostructural transitions between the paramagnetic austenite (Para-A) and the ferromagnetic martensite (Ferro-M) phase occur in limited concentration range. The characteristics of the phase diagram of $\mathrm{Ni}_{2} \mathrm{Mn}_{1-x} \mathrm{Cu}_{x} \mathrm{Ga}(0 \leq x \leq 0.4)$ are closely similar 
to those of $\mathrm{Ni}_{2+x} \mathrm{Mn}_{1-x} \mathrm{Ga}(0 \leq x \leq 0.36)[11,12]$. The effect of the substitution of Fe and Co atoms in Ni-Mn-Ga alloy was studied [13,14]. Recently, Hayasaka et al. determined the phase diagram in the temperature-concentration plane of $\mathrm{Ni}_{2} \mathrm{MnGa}_{1-x} \mathrm{Fe}_{x}(0 \leq x \leq 0.40)$ [15]. The characteristics of the determined phase diagram of $\mathrm{Ni}_{2} \mathrm{MnGa}_{1-x} \mathrm{Fe}_{x}(0 \leq x \leq 0.40)$ are very similar to those of $\mathrm{Ni}_{2+x} \mathrm{Mn}_{1-x} \mathrm{Ga}$ $(0 \leq x \leq 0.36)[11,12]$ and $\mathrm{Ni}_{2} \mathrm{Mn}_{1-x} \mathrm{Cu}_{x} \mathrm{Ga}(0 \leq x \leq 0.4)$ [10], where the magnetostructural transition between Para-A and Ferro-M occurs. However the microscopic understanding of the robust phase diagrams observed in $\mathrm{Ni}_{2+x} \mathrm{Mn}_{1-x} \mathrm{Ga}, \mathrm{Ni}_{2} \mathrm{Mn}_{1-x} \mathrm{Cu}_{x} \mathrm{Ga}$, and $\mathrm{Ni}_{2} \mathrm{MnGa}_{1-x} \mathrm{Fe}_{x}$ is not clear in this stage. Furthermore, there is only a small amount of information about the electric properties of the $\mathrm{Cu}$ and Fe element doped $\mathrm{Ni}_{2} \mathrm{MnGa}$. In this paper, the electric properties are examined experimentally to gain deeper insight into the electronic properties of $\mathrm{Ni}_{2} \mathrm{MnGa}_{1-x} \mathrm{Fe}_{x}$ alloys.

\section{Experimental Procedures}

The experiments were made on the same $\mathrm{Ni}_{2} \mathrm{MnGa}_{1-x} \mathrm{Fe}_{x}(0 \leq x \leq 0.40)$ alloys that were used in our previous studies [15]. Namely, the polycrystalline $\mathrm{Ni}_{2} \mathrm{MnGa}_{1-x} \mathrm{Fe}_{x}(0 \leq x \leq 0.40)$ alloys were prepared by the repeated arc melting of the appropriate quantities of constituent elements, $99.99 \% \mathrm{Ni}$, $99.99 \% \mathrm{Mn}, 99.99 \% \mathrm{Fe}$, and $99.9999 \% \mathrm{Ga}$ in an argon atmosphere. The samples with $x=0.30$ and 0.35 were prepared by the melting of appropriate quantities of the constituent elements with high purity in an induction furnace (DIAVAC LIMITED, Yachiyo, Japan). The reaction products were sealed in evacuated silica tubes, heated at $850^{\circ} \mathrm{C}$ for 3 days and at $600^{\circ} \mathrm{C}$ for 1 day, and then quenched into water. The crystal structure was investigated by X-ray diffraction (Rigaku, Tokyo, Japan) measurements at room temperature using $\mathrm{Cu}-\mathrm{K} \alpha$ radiation. The lattice parameters for the samples were the same as the previous report [15].

The measurements of the electrical resistivity $\rho$ were carried out by a conventional DC (direct current) four-probe method in the temperature range from $80 \mathrm{~K}$ to $450 \mathrm{~K}$. The samples were cut out using a diamond disk saw (BUEHLER, Lake Bluff, IL, USA) into the size of about $1.0 \times 1.0 \times 10 \mathrm{~mm}^{3}$. The thermal process in the measurements started from $80 \mathrm{~K}$, heated up to $450 \mathrm{~K}$, and cooled down again to $80 \mathrm{~K}$.

\section{Results and Discussion}

The temperature dependence of the electrical resistivity $\rho$ of the sample with $x=0.05$ is given in Figure 1a. The obvious slope change near $377 \mathrm{~K}$ is indicative of the ferromagnetic ordering. Below the Curie temperature $T_{C}$, the $\rho$ shows a steep decrease with decreasing temperature. This can be attributed to the disappearance of electron scattering on magnetic fluctuations. The behavior of $\rho$ around $T_{\mathrm{C}}$ is a common feature for the Heusler alloys with ferromagnetic ordering. Assuming that the break point on the $\rho$ vs. $T$ curves corresponds to the Curie temperature of the sample with $x=0.05$, the value of $T_{\mathrm{C}}=377 \mathrm{~K}$ is very close to that determined from the initial permeability $\mu$ vs. $T$ curve [15]. A prominent jump-like feature of $\rho$ appears at around $250 \mathrm{~K}$, indicating the occurrence of the martensitic transition. The martensitic transition temperature $T_{\mathrm{M}}$ was defined by the equation: $T_{\mathrm{M}}=\left(T_{\mathrm{Ms}}+T_{\mathrm{Af}}\right) / 2$, where $T_{\mathrm{Ms}}$ and $T_{\mathrm{Af}}$ are the martensitic transition starting temperature and the reverse martensitic transition finishing temperature, respectively. The values of $T_{\mathrm{Ms}}$ and $T_{\mathrm{Af}}$ were defined as the cross points of the linear extrapolation lines of the $\rho$ vs. $T$ curves from both higher and lower temperature ranges. As shown in Figure 1a, a temperature hysteresis is formed around $T_{\mathrm{M}}$ between $240 \mathrm{~K}$ and $260 \mathrm{~K}$, confirming that the martensitic transition is first-order. On the other hand, such a temperature hysteresis behavior is absent for the ferromagnetic transition around $377 \mathrm{~K}$. With further decrease of temperature from $T_{\mathrm{M}}, \rho$ of the sample with $x=0.05$ represents a typical metallic behavior. The inset in Figure 1a shows the temperature dependence of $d \rho / d T$. A noticeable slope change in $\rho(T)$ around $260 \mathrm{~K}$ marks the onset of the premartensitic transition. The premartensitic transition temperature $T_{\mathrm{p}}$ is estimated to be $264 \mathrm{~K}$, as shown in the inset in Figure 1a. The values of $T_{\mathrm{M}}$ and $T_{\mathrm{p}}$ are in good agreement with those determined from the magnetic measurements earlier [15]. For the sample with $x=0.025$, anomalies on $\mathrm{d} \rho / \mathrm{d} T$ vs. $T$ curves are observed around $T_{\mathrm{p}}$ (see the inset 
in Figure $1 b$. However, as shown in the insets of Figure $1 c-f$, no anomalies on $d \rho / d T$ vs. $T$ curves are observed in the temperature range between $T_{\mathrm{C}}$ and $T_{\mathrm{M}}$, indicating that the premartensitic phase disappears in the concentration range of $x \geq 0.10$. As seen in Figure 1a-f, the martensitic transition temperature increases with increase of Fe concentration $x$. On the other hand, $T_{C}$ increases slightly with $x$.

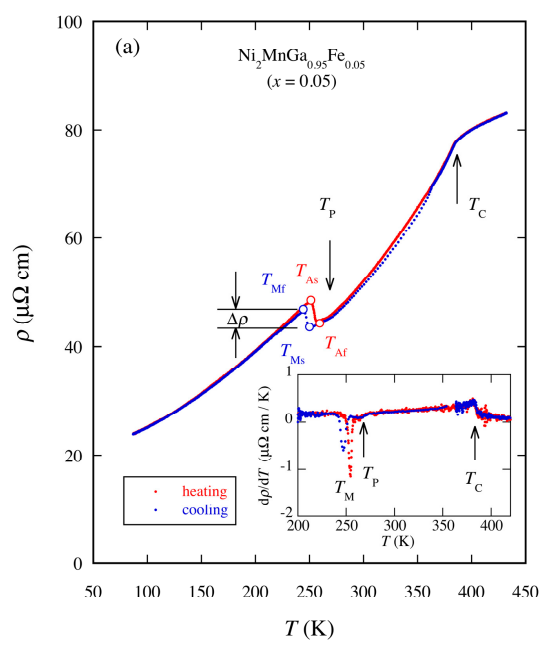

(a)

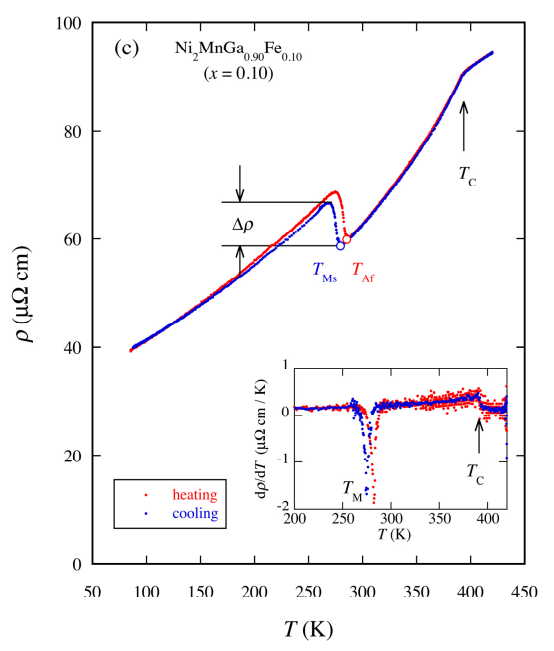

(c)

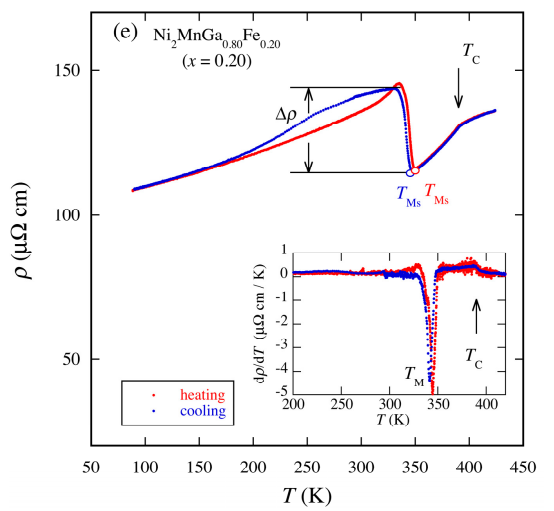

(e)

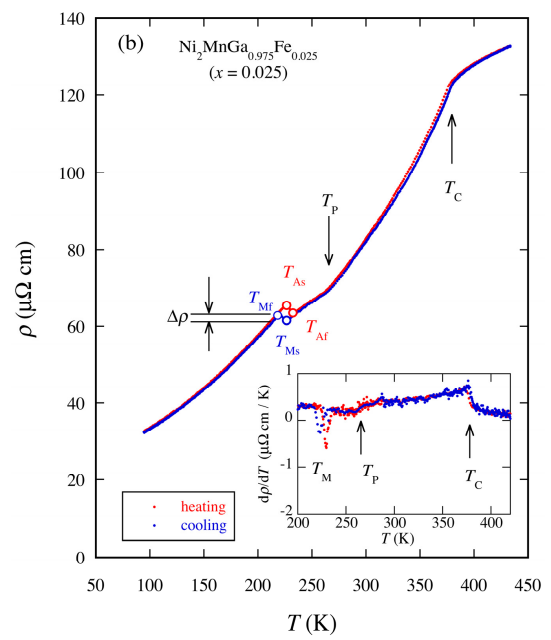

(b)

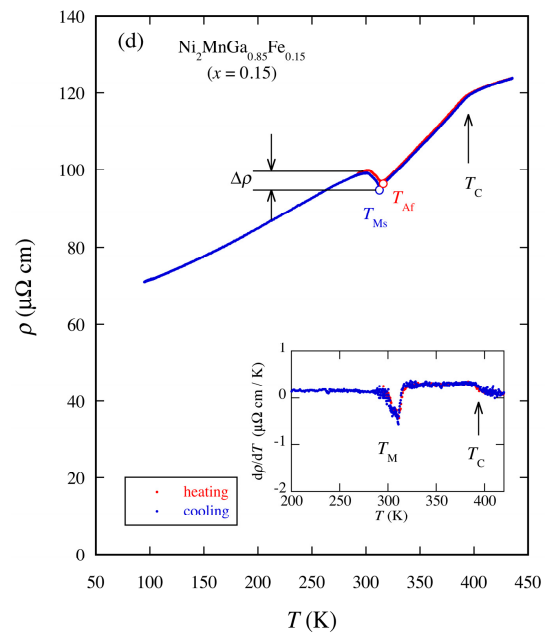

(d)

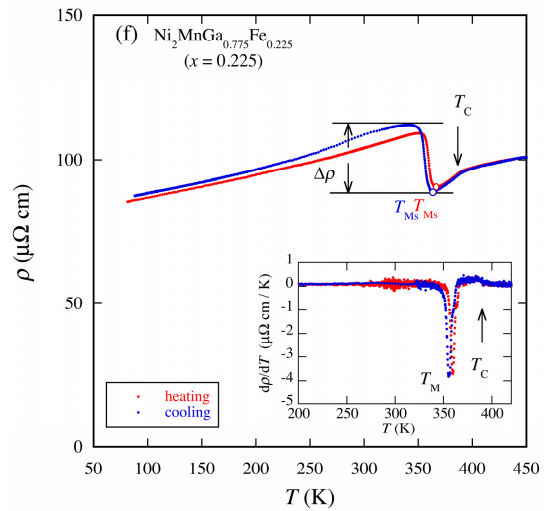

(f)

Figure 1. Cont. 


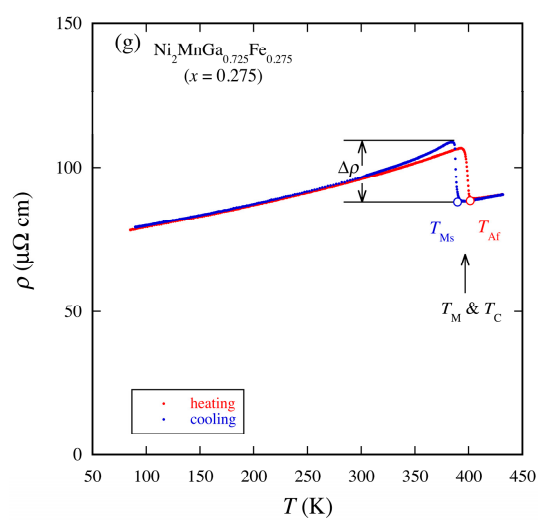

(g)

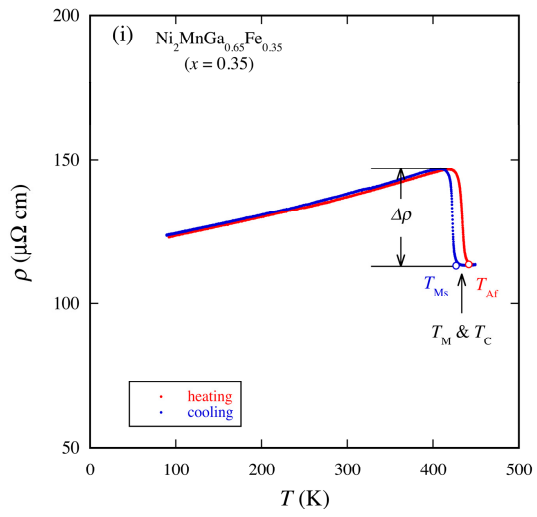

(i)

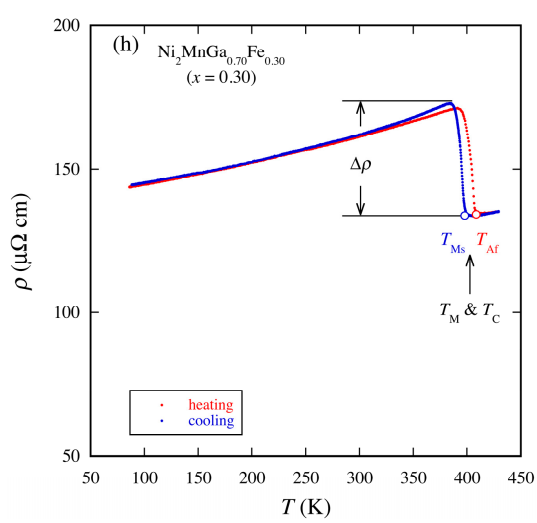

(h)

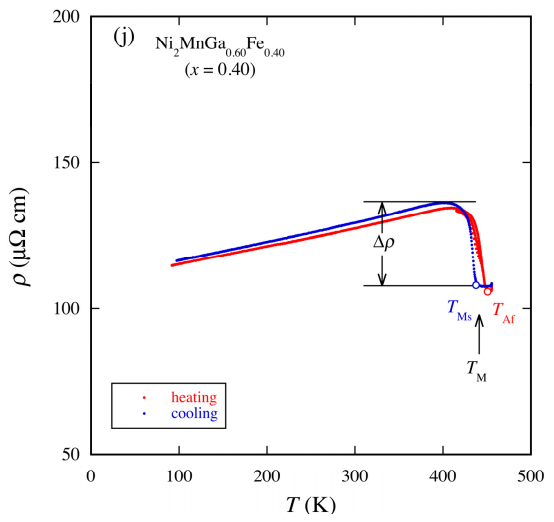

(j)

Figure 1. Temperature dependences of the electrical resistivity $\rho$ for $\mathrm{Ni}_{2} \mathrm{MnGa}_{1-x} \mathrm{Fe}_{x}(x=0.025-0.40)$. The inset shows the temperature dependence of $\mathrm{d} \rho / \mathrm{d} T$. (a) $\mathrm{Ni}_{2} \mathrm{MnGa}_{0.95} \mathrm{Fe}_{0.05} \quad(x=0.05)$; (b) $\mathrm{Ni}_{2} \mathrm{MnGa}_{0.975} \mathrm{Fe}_{0.025}(x=0.025) ;$ (c) $\mathrm{Ni}_{2} \mathrm{MnGa}_{0.90} \mathrm{Fe}_{0.10}(x=0.10)$; (d) $\mathrm{Ni}_{2} \mathrm{MnGa}_{0.85} \mathrm{Fe}_{0.15}(x=0.15)$; (e) $\mathrm{Ni}_{2} \mathrm{MnGa}_{0.80} \mathrm{Fe}_{0.20}(x=0.20)$; (f) $\mathrm{Ni}_{2} \mathrm{MnGa}_{0.775} \mathrm{Fe}_{0.225}$ ( $\left.x=0.225\right) ;\left(\right.$ g) $\mathrm{Ni}_{2} \mathrm{MnGa}_{0.725} \mathrm{Fe}_{0.275}(x=0.275)$; (h) $\mathrm{Ni}_{2} \mathrm{MnGa}_{0.70} \mathrm{Fe}_{0.30}(x=0.30)$; (i) $\mathrm{Ni}_{2} \mathrm{MnGa}_{0.65} \mathrm{Fe}_{0.35}(x=0.35) ;(j) \mathrm{Ni}_{2} \mathrm{MnGa}_{0.60} \mathrm{Fe}_{0.40}$ ( $\left.x=0.40\right)$.

Figure $1 \mathrm{~g}-\mathrm{j}$ show the temperature dependence of $\rho$ for the samples with $x=0.275,0.30,0.35$, and 0.40. According to the phase diagram of $\mathrm{Ni}_{2} \mathrm{MnGa}_{1-x} \mathrm{Fe}_{x}(0 \leq x \leq 0.40)$ reported by Hayasaka et al. [15], the samples with $0.27 \leq x \leq 0.37$ underwent the magnetostructural transition from the Ferro-M state to the Para-A state. For the sample with $x=0.40$, the Ferro-M to the paramagnetic martensite (Para-M) transition appeared. As shown in Figure 1h, the $\rho$ increases abruptly around $402 \mathrm{~K}$ with deceasing temperature, indicating that the magnetic transition between the ferromagnetic phase and the paramagnetic phase was first-order. We did not observe any anomaly below $T_{\mathrm{C}}$ on the $\rho$ vs. $T$ curves, so $T_{M}$ is considered to coincide with $T_{C}$. The $T_{C}\left(=T_{M}\right)$ was estimated to be $402 \mathrm{~K}$ for the sample with $x=0.30$, where $T_{C}$ was defined to be $T_{C}=T_{M}=\left(T_{M s}+T_{\text {Af }}\right) / 2$. Similar $\rho$ vs. $T$ curves are observed for the samples with $x=0.275$ and 0.35 (see Figure $1 \mathrm{~g}, \mathrm{i}$ ). As seen in Figure $1 \mathrm{a}-\mathrm{j}$, the jump of $\rho$ at $T_{\mathrm{M}}, \Delta \rho$, of the samples with $x \geq 0.20$ are considerably larger than that of samples with $0.025 \leq x \leq 0.15$.

Figure 2 shows the concentration dependence of $\Delta \rho$ for $\mathrm{Ni}_{2} \mathrm{MnGa}_{1-x} \mathrm{Fe}_{x}$. As seen in Figure 2, $\Delta \rho$ shows a tendency to increase with increasing $x$, but abruptly increases in the concentration range between $x=0.15$ and 0.20 . 


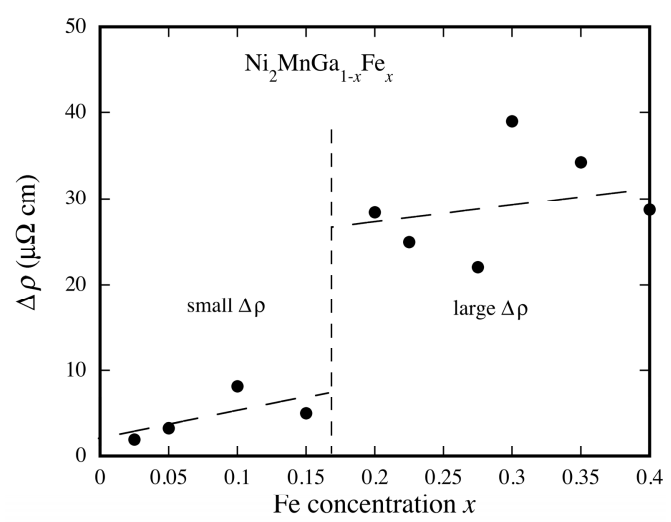

Figure 2. The concentration dependence of $\Delta \rho$ for $\mathrm{Ni}_{2} \mathrm{MnGa}_{1-x} \mathrm{Fe}_{x}(x=0.025-0.40)$. The black dots are $\Delta \rho$ obtained from the experimental data as shown in Figure 1, with dashed lines being guides to the eye. The vertical dotted lines distinguish the electric properties of $\mathrm{Ni}_{2} \mathrm{MnGa}_{1-x} \mathrm{Fe}_{x}$ to two regions.

Figure 3 shows the phase transition temperatures $T_{\mathrm{M}}, T_{\mathrm{p}}$ and $T_{\mathrm{C}}$ determined from the $\rho$ vs. $T$ curves in this study. The closed triangle in the figure represents the phase transition temperature determined from the magnetic measurement [15]. As shown in Figure 3, the phase transition temperatures determined in this study are in good agreement with those reported earlier [15]. The phase diagram of Figure 3 is very similar to those of $\mathrm{Ni}_{2+x} \mathrm{Mn}_{1-x} \mathrm{Ga}(0 \leq x \leq 0.36)[11,12]$ and $\mathrm{Ni}_{2} \mathrm{Mn}_{1-x} \mathrm{Cu}_{x} \mathrm{Ga}(0 \leq x \leq 0.4)$ [10] and $\mathrm{Ni}_{2} \mathrm{MnGa}_{1-x} \mathrm{Cu}_{x}(0 \leq x \leq 0.25)$ [16], as mentioned above. In order to understand the phase diagram of $\mathrm{Ni}_{2} \mathrm{Mn}_{1-x} \mathrm{Cu}_{x} \mathrm{Ga}(0 \leq x \leq 0.4)$, the phenomenological Landau-type free energy as a function of the martensitic distortion and magnetization was constructed and analyzed [10]. Satisfactory agreements between the experiments and theory were obtained, except for the appearance of the premartensitic phase. The analysis showed that the biquadratic coupling term of the martensitic distortion and magnetization plays an important role in the interplay between the martensitic phase and ferromagnetic phase.

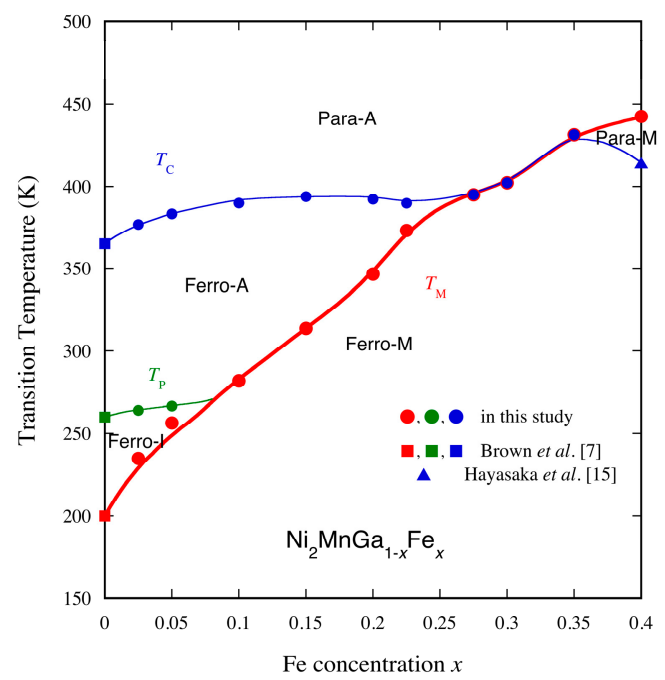

Figure 3. Phase diagram for $\mathrm{Ni}_{2} \mathrm{MnGa}_{1-x} \mathrm{Fe}_{x}(0 \leq x \leq 0.40)$. Para-A and Para-M represent the paramagnetic austenite phase and the paramagnetic martensite phase, respectively. Ferro-A and Ferro-M represent the ferromagnetic austenite phase and the ferromagnetic martensite phase, respectively. Ferro-I means the ferromagnetic premartensite (intermediate) phase. 
The total electrical resistivity is given for usual ferromagnetic materials as follows,

$$
\rho(T)=\rho_{0}+a T+b T^{2},
$$

where $\rho_{0}$ is the residual part, the second term and the third term are the electrical resistivity parts due to electron-phonon scattering and magnetic origin, respectively, with $a$ and $b$ being fitting parameteters. Of course, Equation (1) is a phenomenological fit to the experimental data, and we do not claim that magnetic scattering is purely quadratic in temperature.

Many authors fitted Equation (1) to their experimental data for many Heusler alloys. [17-23]. Table 1 gives the $\rho_{0}, a$, and $b$ values, the validity range of fit, and $T_{C}$ values of $\mathrm{Ni}_{2} \mathrm{MnGa}_{1-x} \mathrm{Fe}_{x}$. The concentration dependence of $\rho_{0}$ determined by fitting the $\rho$ vs. $T$ data $\left(T<T_{\mathrm{M}}\right.$ ) to Equation (1) is shown in Figure 4. As seen in Figure 4, the $\rho_{0}$ value roughly increases with the concentration $x$, but abruptly changes in the concentration range between $x=0.15$ and 0.20 , as well as the behavior of $\Delta \rho$. It can be explained as the impurity effect that the $\rho_{0}$ increases with increasing $x$. The values of $b$ for the samples with $x \leq 0.30$ are two orders of magnitude smaller than those of typical weak itinerant electron ferromagnets $\mathrm{Ni}_{3} \mathrm{Al}, \mathrm{ZrZn}_{2}$ and $\mathrm{Sc}_{3} \mathrm{In}$ [24-27]. A general theory of electrical resistivity in an itinerant electron system has been proposed by Ueda and Moriya on the basis of spin fluctuations [28]. Their work predicts a strong $T^{2}$ dependence of electrical resistivity due to spin fluctuations.

Table 1. The $\rho_{0}(\mu \Omega \mathrm{cm}), a\left(\mu \Omega \mathrm{cm} \mathrm{K}^{-1}\right), b\left(\mu \Omega \mathrm{cm} \mathrm{K}^{-2}\right)$ values according to the fit $\rho(T)=\rho_{0}+a T+b T^{2}$ in the temperature range below $T_{M}$ (i.e., in the Ferro-M (ferromagnetic martensite) phase). The range of validity of the fit, $T_{\mathrm{M}}$ and $T_{\mathrm{C}}$ are given in Table 1.

\begin{tabular}{ccccccc}
\hline Alloys & $\rho_{\mathbf{0}}$ & $\boldsymbol{a} \times \mathbf{1 0}^{-\mathbf{2}}$ & $\boldsymbol{b} \times \mathbf{1 0}^{-\mathbf{4}}$ & Range (K) & $\boldsymbol{T}_{\mathbf{M}}(\mathbf{K})$ & $\boldsymbol{T}_{\mathbf{C}}(\mathbf{K})$ \\
\hline $\mathrm{Ni}_{2} \mathrm{MnGa}_{0.975} \mathrm{Fe}_{0.025}(x=0.025)$ & 22.2 & 4.73 & 6.37 & $100 \sim 220$ & 235 & 383 \\
$\mathrm{Ni}_{2} \mathrm{MnGa}_{0.95} \mathrm{Fe}_{0.05}(x=0.05)$ & 18.2 & 3.34 & 3.54 & $100 \sim 230$ & 257 & 377 \\
$\mathrm{Ni}_{2} \mathrm{MnGa}_{0.90} \mathrm{Fe}_{0.10}(x=0.10)$ & 31.1 & 8.61 & 1.84 & $100 \sim 260$ & 282 & 390 \\
$\mathrm{Ni}_{2} \mathrm{MnGa}_{0.85} \mathrm{Fe}_{0.15}(x=0.15)$ & 60.8 & 9.18 & 1.41 & $100 \sim 270$ & 314 & 393 \\
$\mathrm{Ni}_{2} \mathrm{MnGa}_{0.80} \mathrm{Fe}_{0.20}(x=0.20)$ & 101.6 & 6.47 & 1.67 & $100 \sim 270$ & 347 & 392 \\
$\mathrm{Ni}_{2} \mathrm{MnGa}_{0.775} \mathrm{Fe}_{0.225}(x=0.225)$ & 80.8 & 5.25 & 0.84 & $100 \sim 320$ & 356 & 390 \\
$\mathrm{Ni}_{2} \mathrm{MnGa}_{0.725} \mathrm{Fe}_{0.275}(x=0.275)$ & 75.0 & 4.91 & 0.86 & $100 \sim 350$ & 395 & 395 \\
$\mathrm{Ni}_{2} \mathrm{MnGa}_{0.70} \mathrm{Fe}_{0.30}(x=0.30)$ & 139 & 4.42 & 1.04 & $100 \sim 370$ & 402 & 402 \\
$\mathrm{Ni}_{2} \mathrm{MnGa}_{0.65} \mathrm{Fe}_{0.35}(x=0.35)$ & 118 & 5.06 & 0.43 & $100 \sim 390$ & 431 & 431 \\
$\mathrm{Ni}_{2} \mathrm{MnGa}_{0.60} \mathrm{Fe}_{0.40}(x=0.40)$ & 110 & 5.27 & 0.26 & $100 \sim 390$ & 442 & $414^{1}$ \\
\hline
\end{tabular}

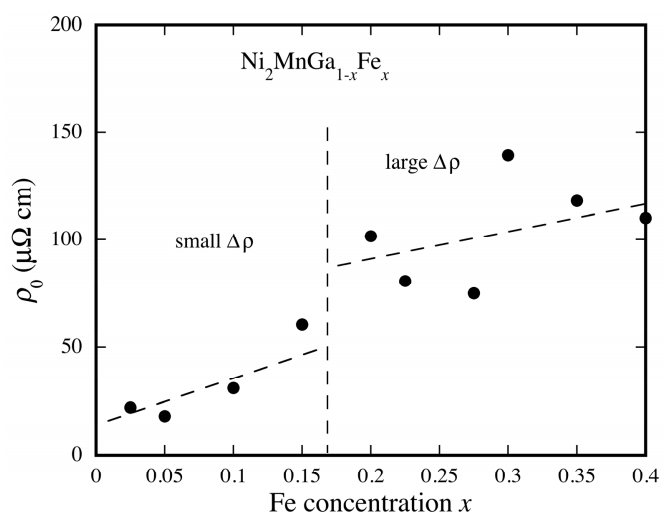

Figure 4. The concentration dependence of the residual electrical resistivity $\rho_{0}$ for $\mathrm{Ni}_{2} \mathrm{MnGa}_{1-x} \mathrm{Fe}_{x}$. The black dots are $\rho_{0}$ obtained from the analyzed data as shown in Table 1, with dashed lines being guides to the eye. The vertical dotted lines distinguish the electric properties of $\mathrm{Ni}_{2} \mathrm{MnGa}_{1-x} \mathrm{Fe}_{x}$ to two regions. 
In this study, as shown in Figures 2 and 4, we found the borderline which distinguishes the electric properties of $\mathrm{Ni}_{2} \mathrm{MnGa}_{1-x} \mathrm{Fe}_{x}(0 \leq x \leq 0.40)$ alloys. The Fe concentration variation on the temperature dependence of resistivity for $\mathrm{Ni}_{2} \mathrm{MnGa}_{1-x} \mathrm{Fe}_{x}(0 \leq x \leq 0.40)$ alloys may be caused by the change of the charge carrier concentration between the martensite and austenite phases or the change of the mechanism of the martensitic transition. Now, it is not clear for the origin of appearance of the borderline. This may be related to the electron scattering at the twin and domain boundaries which appear in the martensitic phase. An investigation of microstructure observation will also be necessary.

\section{Conclusions}

Temperature dependences of the electrical resistivity have been measured on the Heusler alloy system $\mathrm{Ni}_{2} \mathrm{MnGa}_{1-x} \mathrm{Fe}_{x}$. The phase diagram of $\mathrm{Ni}_{2} \mathrm{MnGa}_{1-x} \mathrm{Fe}_{x}$ was constructed on the basis of the experimental results. The magnetostructural transitions were observed at the Fe concentrations $x=0.275,0.30$, and 0.35 in $\mathrm{Ni}_{2} \mathrm{MnGa}_{1-x} \mathrm{Fe}_{x}$ alloys as well as a previous report [15]. The changes of the electrical resistivity at the martensitic transition temperature were studied as the function of Fe concentration $x$.

Acknowledgments: The authors would like to express our sincere thanks to Toetsu Shishido and Kazuo. Obara of Institute for Materials Research, Tohoku University (Sendai, Japan) for their help on the sample preparation. This study was partly supported by a Grant-in-Aid for Scientific Research, provided by the Japan Society for the Promotion of Science.

Author Contributions: Yoshiya Adachi and Takeshi Kanomata conceived and designed the experiments; Yuki Ogi, Noriaki Kobayashi, Yuki Hayasaka, Rie Y Umetsu and Xiao Xu performed the experiments; Xiao Xu and Ryosuke Kainuma analyzed the data; Yoshiya Adachi, Xiao Xu and Takeshi Kanomata wrote the paper.

Conflicts of Interest: The authors declare no conflict of interest.

\section{References}

1. Brown, P.J.; Kanomata, T.; Matsumoto, M.; Neumann, K.-U.; Ziebeck, K.R.A. Magnetism and Structure in Functional Materials; Planes, A., Mañosa, L., Saxena, A., Eds.; Springer: Berlin/Heiderberg, Germany, 2005; pp. 113-140.

2. Kainuma, R.; Imano, Y.; Ito, W.; Sutou, Y.; Morito, H.; Okamoto, S.; Kitakami, O.; Oikawa, K.; Fujita, A.; Kanomata, T.; et al. Magnetic-field-induced shape recovery by reverse phase transformation. Nature 2006, 439, 957-960. [CrossRef] [PubMed]

3. Planes, A.; Mañosa, L.; Acet, M. Magnetocaloric effect and its relation to shape-memory properties in ferromagnetic Heusler alloys. J. Phys. Condens. Matter 2009, 21, 233201. [CrossRef] [PubMed]

4. Chernenko, V.A. (Ed.) Advances in Magnetic Shape Memory Materials; Trans. Tech. Publications Ltd.: Zurich, Switzerland, 2011.

5. Acet, M.; Mañosa, L.I.; Planes, A. Magnetic-Field-Induced Effects in Martensitic Heusler-Based Magnetic Shape Memory Alloys. In Handbook of Magnetic Materials; Elsevier Science: Amsterdam, The Netherlands, 2011.

6. Yu, G.H.; Xu, Y.L.; Liu, Z.H.; Qiu, H.M.; Zhu, Z.Y.; Huang, X.P.; Pan, L.Q. Recent progress in Heusler-type magnetic shape memory alloys. Rare Met. 2015, 34, 527-539. [CrossRef]

7. Brown, P.J.; Crangle, J.; Kanomata, T.; Matsumoto, M.; Neumann, K.U.; Ouladdiaf, B.; Ziebeck, K.R.A. The crystal structure and phase transitions of the magnetic shape memory compound $\mathrm{Ni}_{2} \mathrm{MnGa}$. J. Phys. Condens. Matter 2002, 14, 10159-10171. [CrossRef]

8. Singh, S.; Bednarcik, J.; Barman, S.R.; Felser, C.; Pandey, D. Premartensite to martensite transition and its implications for the origin of modulation in $\mathrm{Ni}_{2} \mathrm{MnGa}$ ferromagnetic shape-memory alloy. Phys. Rev. B 2015, 92, 054112. [CrossRef]

9. Singh, S.; Petricek, V.; Rajput, P.; Hill, A.H.; Suard, E.; Barman, S.R.; Pandey, D. High-resolution synchrotron $\mathrm{X}$-ray powder diffraction study of the incommensurate modulation in the martensite phase of $\mathrm{Ni}_{2} \mathrm{MnGa}$ : Evidence for nearly 7M modulation and phason broadening. Phys. Rev. B 2014, 90, 014109. [CrossRef] 
10. Kataoka, M.; Endo, K.; Kudo, N.; Kanomata, T.; Nishihara, H.; Shishido, T.; Umetsu, R.Y.; Nagasako, M.; Kainuma, R. Martensitic transition, ferromagnetic transition, and their interplay in the shape memory alloys $\mathrm{Ni}_{2} \mathrm{Mn}_{1-x} \mathrm{Cu}_{x}$ Ga. Phys. Rev. B 2010, 82, 214423. [CrossRef]

11. Vasil'ev, A.N.; Bozhko, A.D.; Khovailo, V.V.; Dikshtein, I.E.; Shavrov, V.G.; Buchelnikov, V.D.; Matsumoto, M.; Suzuki, S.; Takagi, T.; Tani, J. Structural and magnetic phase transitions in shape-memory alloys $\mathrm{Ni}_{2+x} \mathrm{Mn}_{1-x}$ Ga. Phys. Rev. B 1999, 59, 1113-1120. [CrossRef]

12. Khovaylo, V.V.; Buchelnikov, V.D.; Kainuma, R.; Koledov, V.V.; Ohtsuka, M.; Shavrov, V.G.; Takagi, T.; Taskaev, S.V.; Vasiliev, A.N. Phase transitions in $\mathrm{Ni}_{2+x} \mathrm{Mn}_{1-x}$ Ga with a high Ni excess. Phys. Rev. B 2005, 72, 224408. [CrossRef]

13. Soto, D.; Hernández, V.A.; Flores-Zúñiga, H.; Moya, X.; Mañosa, L.; Planes, A.; Aksoy, S.; Acet, M.; Krenke, T. Phase diagram of Fe-doped Ni-Mn-Ga ferromagnetic shape-memory alloys. Phys. Rev. B 2008, 77, 184103. [CrossRef]

14. Soto-Parra, D.E.; Moya, X.; Mañosa, L.; Planes, A.; Flores-Zúñiga, H.; Alvarado-Hernández, F.; Ochoa-Gamboa, R.A.; Matutes-Aquino, J.A.; Ríos-Jara, D. Fe and Co selective substitution in $\mathrm{Ni}_{2} \mathrm{MnGa}^{\mathrm{M}}$ Effect of magnetism on relative phase stability. Philos. Mag. 2010, 90, 2771-2792. [CrossRef]

15. Hayasaka, Y.; Aoto, S.; Date, H.; Kanomata, T.; Xu, X.; Umetsu, R.Y.; Nagasako, M.; Omori, T.; Kainuma, R.; Sakon, T.; et al. Magnetic phase diagram of ferromagnetic shape memory alloys $\mathrm{Ni}_{2} \mathrm{MnGa}_{1-x} \mathrm{Fe}_{x}$. J. Alloys Compd. 2014, 591, 280-285. [CrossRef]

16. Endo, K.; Kanomata, T.; Kimura, A.; Kataoka, M.; Nishihara, H.; Umetsu, R.Y.; Obara, K.; Shishido, T.; Nagasako, M.; Kainuma, R.; et al. Magnetic phase diagram of the ferromagnetic shape memory alloys $\mathrm{Ni}_{2} \mathrm{MnGa}_{1-x} \mathrm{Cu}_{x}$. Mater. Sci. Forum 2011, 684, 165-176. [CrossRef]

17. Kunzler, J.V.; Grandi, T.A.; Schreiner, W.H.; Pureur, P.; Brandão, D.E. Electrical resistivity measurements on the $\mathrm{Cu}_{2} \mathrm{MnAl}$ heusler alloy. J. Phys. Chem. Solids 1979, 40, 427-429. [CrossRef]

18. Kunzler, J.V.; Grandi, T.A.; Schreiner, W.H.; Pureur, P.; Brandão, D.E. Spin-disorder resistivity in the $\mathrm{Cu}_{2} \mathrm{Mn}\left(\mathrm{Al}_{1-x} \mathrm{Sn}_{x}\right)$ Heusler alloys. J. Phys. Chem. Solids 1980, 41, 1023-1026. [CrossRef]

19. Schreiner, W.H.; Brandão, D.E.; Ogiba, F.; Kunzler, J.V. Electrical resistivity of Heusler alloys. J. Phys. Chem. Solids 1982, 43, 777-780. [CrossRef]

20. Zhang, M.; Liu, G.; Cui, Y.; Hu, H.; Liu, Z.; Chen, J.; Wu, G.; Sui, Y.; Qian, Z.; Zhang, X. Magnetism and transport properties of melt-spun ribbon $\mathrm{Cu}_{2} \mathrm{MnAl}$ Heusler alloy. J. Magn. Magn. Mater. 2004, 278, 328-333. [CrossRef]

21. Marchenkova, E.B.; Kourov, N.I.; Marchenkov, V.V.; Pushin, V.G.; Korolev, A.V.; Weber, H.W. Low temperature kinetic properties and structure of $\mathrm{Ni}_{50+x} \mathrm{Mn}_{25-\mathrm{x}+\mathrm{y}} \mathrm{Ga}_{25-\mathrm{y}}$ alloys with shape memory. J. Phys. Conf. Ser. 2009, 150, 022054. [CrossRef]

22. Ingale, B.; Gopalan, R.; Chandrasekaran, V.; Ram, S. Structural, magnetic, and magnetotransport studies in bulk Ni ${ }_{55.2} \mathrm{Mn}_{18.1} \mathrm{Ga}_{26.7}$ alloy. J. Appl. Phys. 2009, 105, 023903. [CrossRef]

23. Kourov, N.I.; Marchenkov, V.V.; Pushin, V.G.; Belozerova, K.A. Electrical properties of ferromagnetic $\mathrm{Ni}_{2} \mathrm{MnGa}$ and $\mathrm{Co}_{2} \mathrm{CrGa}$ Heusler alloys. J. Exp. Theor. Phys. 2013, 117, 121-125. [CrossRef]

24. Fluitman, J.H.J.; Boom, R.; De Chatel, P.F.; Schinkel, C.J.; Tilanus, J.L.L.; De Vries, B.R. Possible explanations for the low temperature resistivities of $\mathrm{Ni}_{3} \mathrm{Al}$ and $\mathrm{Ni}_{3} \mathrm{Ga}$ alloys in terms of spin density fluctuation theories. J. Phys. F Met. Phys. 1973, 3, 109-117. [CrossRef]

25. Yoshizawa, M.; Seki, H.; Ikeda, K.; Okuno, K.; Saito, M.; Shigematsu, K. Magnetic field effects on electrical resistivity and ferromagnetism in $\mathrm{Ni}_{3} \mathrm{Al}$ alloys. J. Phys. Soc. Jpn. 1992, 61, 3313-3321. [CrossRef]

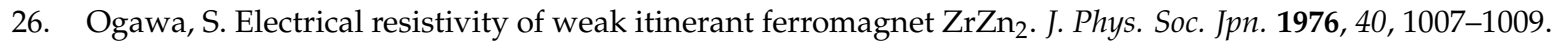
[CrossRef]

27. Ikeda, K.; Gschneider, K.A., Jr.; Kobayashi, N.; Noto, K. Magnetoresistance of Sc 3 In. J. Magn. Magn. Mater. 1984, 42, 1-11. [CrossRef]

28. Ueda, K.; Moriya, T. Contribution of spin fluctuations to the electrical thermal resistivities of weakly and nearly ferromagnetic metals. J. Phys. Soc. Jpn. 1975, 39, 605-615. [CrossRef]

(C) 2017 by the authors. Licensee MDPI, Basel, Switzerland. This article is an open access article distributed under the terms and conditions of the Creative Commons Attribution (CC BY) license (http:/ / creativecommons.org/licenses/by/4.0/). 